\title{
Mind the Gap: A Journey to Sustainable Supply Chains
}

\author{
Sean Ansett
}

Published online: 23 December 2007

(C) Springer Science + Business Media, LLC 2007

\section{Erratum to: Employ Respons Rights J DOI 10.1007/s10672-007-9055-x}

The correct version of abstract is given below.

\begin{abstract}
Many companies take a myopic view on Corporate Social Responsibility (CSR) focusing solely on philanthropy and avoid addressing their material issues. There are a few companies that have begun to see the strategic advantages of being socially responsible and addressing their social, environmental and economic challenges. Developing an effective strategy can reward companies with reputation enhancement, license to operate, avoiding litigation, recruitment and retention of employees and developing process, product and strategic innovations. One company who has realized the value of investing and integrating CSR into their core business model is the global retailer Gap Inc. This article will examine Gap Inc.'s evolution in the CSR space and its work developing an effective labor standards assurance program and stakeholder engagement strategy transforming historically adversarial relationships with key stakeholders into collaborative multi-stakeholder partnerships. Particular attention is put towards Gap Inc.'s learnings in the process and how these new insights innovated the company's CSR strategy over time.
\end{abstract}

The online version of the original article can be found at http://dx.doi.org/10.1007/s10672-007-9055-x.

S. Ansett $(\square)$

Calle San Mateo 18, 3 piso Centro, Madrid, Spain 28004

e-mail: sean@atstakeadvisors.com 